\title{
Clinical evaluation of women with PMB. Is it always necessary an endometrial biopsy to be performed? A review of the literature
}

\author{
Marina Dimitraki · Panagiotis Tsikouras · Sophia Bouchlariotou • \\ Alexandros Dafopoulos • Vasileios Liberis · Georgios Maroulis • \\ Alexander Tobias Teichmann
}

Received: 2 February 2010 / Accepted: 11 July 2010 / Published online: 4 August 2010

(c) The Author(s) 2010. This article is published with open access at Springerlink.com

\begin{abstract}
Background Endometrial carcinoma is the most distressing cause of abnormal vaginal bleeding. The intention of clinical management in the case of postmenopausal bleeding is to achieve an accurate diagnosis without overinvestigation.

Method We studied the available literature on the diagnostic evaluation of postmenopausal women with vaginal bleeding, accentuating the most important aspects on this topic: the accuracy of sonography and endometrial biopsy in predicting endometrial hyperplasia and endometrial carcinoma.

Results The accuracy of the above tests in predicting endometrial hyperplasia and endometrial carcinoma is a subject of continuing debate. Moreover, in the last decades, there has been an explosion of publications indicating that ultrasound may be useful in predicting endometrial pathology.

Conclusion Since advanced endometrial carcinoma has been known to occur in cases without noticeable endometrial thickness on ultrasound, the clinician should beware of the diagnostic evaluation of postmenopausal women with vaginal bleeding.
\end{abstract}

Keywords Postmenopausal bleeding $\cdot$ Endometrial thickness · Biopsy

M. Dimitraki · P. Tsikouras $(\bowtie) \cdot$ S. Bouchlariotou ·

A. Dafopoulos · V. Liberis · G. Maroulis

Department of Obstetrics and Gynecology,

University Hospital of Alexandroupolis,

Democritus University of Thrace,

68100 Alexandroupolis, Greece

e-mail: ptsikour@med.duth.gr

\section{A. T. Teichmann}

Department of Obstetrics and Gynecology,

Teaching Hospital of Aschaffenburg,

Aschaffenburg, Germany

\section{Introduction}

Endometrial cancer is predominantly a disease of postmenopausal women, most cases occurring in the sixth and seventh decades, with less than $5 \%$ of cases in women under 40 years of age. The lifetime risk of developing endometrial cancer is $1.1 \%$ while the lifetime risk of dying of endometrial cancer is $0.4 \%$, reflecting the good prognosis of the condition with early diagnosis [1]. Vaginal bleeding is the presenting sign in more than $90 \%$ of postmenopausal patients with endometrial carcinoma. However, depending on age and risk factors, $1-14 \%$ will have endometrial cancer [1, 2].

One concern in treating women with postmenopausal bleeding (PMB) is whether the appropriate initial method of evaluating is TVUS, endometrial biopsy or both.

Until the 1980s, fractional dilation and curettage (d\&c) was the procedure most often used. Although d\&c is invasive and is associated with a 1-2\% complication rate, it often suggests the extent of the disease and the tumor mass [3]. However, the use of the d\&c for the assessment of endometrial pathology has serious limitations, as it has a false-negative rate of between 2 and $6 \%$ for diagnosing endometrial cancer and hyperplasia, while the rate of falsepositive results in the cervical fraction approaches $50 \%$.

Diagnostic hysteroscopy with directed biopsy, if indicated, is an option, particularly for patients with recurrent bleeding despite negative curettage. It provides additional information and accuracy by detecting early foci of cancer that can be missed by curettage - this operation permits taking directed biopsies, thereby minimizing the theoretical risk of sampling errors. Hysteroscopy can also evaluate cervical involvement better than fractional curettage.

Transvaginal ultrasound is a simple, non-invasive technique that can be used to discriminate between benign and malignant endometrium, offers a sensitive view to pelvic 
pathology and has been explored as an alternative technique to indirectly visualize the endometrium. It is used today increasingly in the diagnostic work-up of patients with endometrial cancer. It has high sensitivity and specificity as a screening method in postmenopausal patients. The odds of endometrial cancer after a negative scan (endometrial thickness $\leq 4 \mathrm{~mm}$ ) are only one-tenth of the odds before the scan $[4,5]$. The use of hydrosonography has led to a significant increase in the diagnostic accuracy of transvaginal ultrasonography. Some have suggested that color and spectral Doppler ultrasound examination of the uterine and subendometrial arteries can aid in the differentiation between benign and malignant endometrium [6-9].

There are conflicting reports about the best way of initial investigation of endometrial pathology and the aim of this study is to summarize the currently available published literature on the diagnostic accuracy of pelvic ultrasonography and endometrial biopsy for predicting endometrial carcinoma and disease (hyperplasia and/or carcinoma).

\section{TVUS versus histological evaluation}

The accuracy of TVUS and endometrial histological biopsy in predicting endometrial hyperplasia and endometrial carcinoma is a subject of continuing debate. Karlsson et al. [10] compared the specificity and sensitivity of transvaginal ultrasound and $\mathrm{d} \& \mathrm{c}$ to discriminate between a normal and pathological endometrium. A specificity of $81 \%$ and a sensitivity of $97 \%$ in diagnosing morphological alterations by means of TVUS were found. Moreover, other authors [11] determine the sensitivity and specificity for the measurement of endometrial thickness using TVUS to diagnose an endometrial abnormality at 100 and $75 \%$, respectively. The corresponding figures for hysteroscopy were 97 and $88 \%$.

In a recent meta-analysis [12] of endometrial sampling methods, sensitivity for detection of endometrial carcinoma was in the range of $25-100 \%$. The best results were from a single study of pipelle endometrial biopsy in postmenopausal women, with sensitivity of $99.6 \%$. False-negative rates for office-based endometrial biopsy have been reported at more than $15 \%$ and d\&c has up to an $11 \%$ falsenegative rate for endometrial carcinoma. One study reported that endometrial biopsy had only a $43 \%$ sensitivity rate for detecting endometrial carcinoma. False-positive rates for endometrial biopsy are believed to be very low, although no exact figure has been reported.

\section{Abnormal endometrial thickness}

With TVUS, it has been shown that the endometrial thickness of normal atrophic uterus measures on average $2.3 \mathrm{~mm}$
[13, 14]. However, advanced endometrial carcinoma has also been known to occur in cases without noticeable endometrial thickness on ultrasound $[15,16]$.

In a study of postmenopausal women without uterine bleeding [3, 15], a mean endometrial thickness of $3.2 \mathrm{~mm}$ was reported. Subsequently, it was reported [13] that the mean endometrial thickness for women with PMB and a histopathological diagnosis of atrophy was $3.4 \mathrm{~mm}$. However, in the Nordic multicenter study of over 1,000 women with PMB, the corresponding figure was found to be $3.9 \mathrm{~mm}$ (range 1-2 mm) [3, 10] (Table 1).

The data relating to endometrial thickness in the presence of carcinoma do not always demonstrate a concordance. Some authors have suggested a 3-mm thickness as a threshold, to reduce the chance of missing cases of carcinoma at the expense of specificity. Auslender et al. [11] used a cut-off limit of $3 \mathrm{~mm}$ and suggested that an endometrial thickness of $3 \mathrm{~mm}$ or less as a threshold would have reduced the number of $\mathrm{d} \& \mathrm{c}$ procedures by $45 \%$ and no cases of endometrial pathologies would have been missed. Nonetheless, in another study [16], three of nine cases of carcinoma were found in women with an endometrial thickness of $3 \mathrm{~mm}$. (However, this study also reported mean endometrial thickness lower than those in most studies, e.g. $6 \mathrm{~mm}$ in cases of carcinoma, suggesting that a difference in technique may partially account for the findings.)

The earliest reports comparing TVUS with endometrial sampling consistently found that an endometrial thickness of less than or equal to $4-5 \mathrm{~mm}$ in patients with PMB reliably excluded endometrial cancer. Botsis et al. [17] reported that the mean endometrial thickness in women, examined in their study, with endometrial cancer was $16.6 \pm 5.4 \mathrm{~mm}$ as compared with $3.2 \pm 1.1 \mathrm{~mm}$ in those women with atrophic endometrium, and $9.5 \pm 2.3 \mathrm{~mm}$ in those with hyperplasia and concluded that, if a cut-off limit of $5 \mathrm{~mm}$ had been used in the study, a single case of serious endometrial pathology would not have been missed.

Subsequently, Karlsson et al. [10] in the Nordic multicenter trial, the largest study evaluating endometrial measurements in postmenopausal women with bleeding, found that in women with endometrial cancer the mean endometrial thickness $\pm \mathrm{SD}$ was $21.1 \pm 11.8 \mathrm{~mm}$. No malignant endometrium was

Table 1 Endometrial thickness related to the histopathological diagnosis of atrophy in women with postmenopausal bleeding, in some published papers

\begin{tabular}{llll}
\hline & Year & $\begin{array}{l}\text { Mean thickness } \\
(\mathrm{mm}) \pm \mathrm{SD}\end{array}$ & $\begin{array}{l}\text { Range } \\
(\mathrm{mm})\end{array}$ \\
\hline Granberg et al. [13] & 1991 & $3.4 \pm 1.2$ & $2-11$ \\
Botsis et al. [17] & 1992 & $3.2 \pm 1.1$ & - \\
Auslender [11] & 1993 & $2.6 \pm 1.4$ & $0-6.5$ \\
Karlsson et al. [10] & 1993 & $3.9 \pm 2.5$ & $1-22$ \\
\hline
\end{tabular}


thinner than $5 \mathrm{~mm}$. In 30 women (2.8\%), it was not possible to measure the thickness of the endometrium. The $95 \%$ confidence limit for the probability of excluding endometrial abnormality was $5.5 \%$ when the endometrial thickness was $\leq 4 \mathrm{~mm}$, as measured by TVUS. They stated that the risk of finding pathologic endometrium at curettage when the endometrium is $\leq 4 \mathrm{~mm}$, as measured by TVUS, is $5.5 \%$.

Similarly, Ferrazzi et al. [18] used the same cut-off of $4 \mathrm{~mm}$ with the likelihood ratio (LR) for cancer, yielded, by an endometrial thickness of $\leq 4.0 \mathrm{~mm}, 0.05$. This cut-off of $4.0 \mathrm{~mm}$ yielded a sensitivity for the detection of cancer of $98 \%$ and a negative predictive value of $99 \%$. They have shown that an endometrial thickness of $\leq 4.0 \mathrm{~mm}$ safely predicts endometrial atrophy and justifies expectant management, when the patient understands the need for proper follow-up. This could be achieved with a reduction in the use of invasive procedures without unwanted delay in cancer diagnosis.

Since that time, a number of confirmatory multicenter trials have been completed. It has been found [19] that endometrial cancer occurs most in women without HRT, particularly in those women with an endometrium exceeding $8 \mathrm{~mm}$. Consequently, it has been demonstrated that the cut-off for excluding endometrial abnormalities is $\leq 4 \mathrm{~mm}$. In a subsequent study [20], an evaluation of 419 women with PMB assessed the sensitivity of 2 endometrial thickness thresholds: 4 and $8 \mathrm{~mm}$. The authors reported a diagnostic sensitivity of $95.1 \%$ and a specificity of $54.8 \%$ when using the 4-mm cut-off, and an $83.8 \%$ sensitivity and $81.3 \%$ specificity when using the 8 -mm cut-off.

A prospective diagnostic accuracy study [21] had the following results: Using endometrial thickness $\leq 4 \mathrm{~mm}$, the sensitivity of ultrasound to detect the endometrial malignancy was $92.9 \%$, the specificity was $100 \%$, and the positive and negative predictive values were 24.1 and $97.6 \%$, respectively. Analysis using LR revealed that LR was 0.14 for endometrial thickness $\leq 4.0 \mathrm{~mm}, 0.94$ for endometrial thickness 4.1-9.0 mm, and 3.3 for endometrial thickness > $9.0 \mathrm{~mm}$. The study concluded that in women with PMB, malignancy can probably be safely excluded if sonographic endometrial thickness is $\leq 4.0 \mathrm{~mm}$.

In concordance, the study of Ciatto et al. [22] suggested that the best cut-off for clinical purposes is $4 \mathrm{~mm}$, with a sensitivity of $91.1 \%$, a specificity of $79.8 \%$, a positive predictive value of $14.8 \%$ and a negative predictive value of $99.6 \%$. Moreover, in a subsequent study, Guner et al. [23] also concluded that endometrial thickness of $<4 \mathrm{~mm}$ may serve as cut-off point for predicting pathology negative cases with an accuracy of $100 \%$ in postmenopausal women with or without vaginal bleeding. Then, as the endometrial thickness increases, the probability of finding endometrial pathology in curettage increases linearly with a positive predictive value of $74.6 \%$.
Despite these encouraging results, Tsikouras et al. [24] in a retrospective study, which included 275 patients with $\mathrm{PMB}$, reported a $8.16 \%$ prevalence of endometrial cancer in women with PMB and endometrial thickness $<4 \mathrm{~mm}$. Using a maximum 5-mm endometrial thickness, in a study of 182 women with PMB [25], no cases of carcinoma were found; however, 3 patients had hyperplasia.

Another prospective study [26] tried to evaluate the optimum method(s) of investigating women with PMB. The authors concluded that an endometrial thickness of $>5 \mathrm{~mm}$ used as an indicator of endometrial pathology compared to uterine curettage has a sensitivity of $83 \%$, a specificity of $77 \%$, and a positive predictive value of $54 \%$.

Bruchim et al. [27] found that no patient had carcinoma when the endometrium was less than 5-mm thick, but $18.5 \%$ did when the thickness exceeded $9 \mathrm{~mm}$, with the mean endometrial thickness in the presence of endometrial carcinoma $13.5 \mathrm{~mm}( \pm 7.7 \mathrm{~mm})(p<0.005)$.

In addition, a recent study [28] reported a $0.6 \%$ prevalence of endometrial cancer in women with PMB and endometrial thickness $<4 \mathrm{~mm}$. This prevalence increased to $19 \%$ in women with an endometrial thickness $\geq 5 \mathrm{~mm}$. The authors concluded that in women with an endometrial thickness $<4 \mathrm{~mm}$, endometrial biopsy is not required [29].

Other authors suggest that a minimum sonographically measured endometrial thickness of $6 \mathrm{~mm}$ should be utilized to reduce the number of false positives [15, 30]. Mateos et al. [31] reported a prospective trial of TVUS evaluation followed by endometrial sampling in 168 women with PMB who were not receiving estrogen. They resulted in $88.6 \%$ sensitivity, $90.6 \%$ specificity, and $92 \%$ positive predictive value for any endometrial pathology, using a cut-off of $6 \mathrm{~mm}$ for endometrial thickness.

It is worthy of note that it has been reported [27] that endometrial thickness and years of menopause define cut-off points for the diagnostic biopsy of tissue samples for endometrial carcinoma $(6 \mathrm{~mm}$ of endometrial thickness for women experiencing menopause $5-15$ years prior and $5 \mathrm{~mm}$ in those going through menopause 15 or more years prior).

In summary, it seems that a minimum thickness of $5 \mathrm{~mm}$ as the threshold for follow-up [31] biopsy would provide adequate sensitivity without excessive false-positive rates in most women and a false-negative rate of $0.25-0.50 \%$ [33, 34].

On the other hand, several studies suggest that an endometrial thickness of $>15 \mathrm{~mm}$ is highly suggestive of endometrial carcinoma [35] (Tables 2, 3).

\section{Endometrial biopsy. Is it a necessity?}

Given that more than $90 \%$ of postmenopausal and more than $98 \%$ of pre- and perimenopausal women with abnormal bleeding will have a benign underlying cause, questions 
Table 2 Endometrial thickness and cancer findings in postmenopausal women with bleeding

\begin{tabular}{llccl}
\hline Reference & $\begin{array}{l}\text { Endometrial } \\
\text { thickness (mm) }\end{array}$ & $\begin{array}{l}\text { Number of } \\
\text { women }\end{array}$ & $\begin{array}{l}\text { Number of cases } \\
\text { of cancer }\end{array}$ & $\begin{array}{l}\text { Negative predictive } \\
\text { value (\%) }\end{array}$ \\
\hline Karlsson et al. [10] & $\leq 4$ & 1,168 & 0 & 100 \\
Ferrazzi et al. [18] & $\leq 4$ & 930 & 2 & 99.8 \\
& $\leq 5$ & & 4 & 99.6 \\
Gull et al. [28] & $\leq 4$ & 163 & 1 & 99.4 \\
Epstein et al. [32] & $\leq 5$ & 97 & 0 & 100 \\
Gull et al. [29] & $\leq 4$ & 394 & 0 & 100 \\
Bruchim et al. [27] & $\leq 5$ & 95 & 0 & 100 \\
Epstein and Valentin [6] & $\leq 4.5$ & 95 & 12 & 87.4 \\
Tsikouras et al. [24] & $\leq 4$ & 275 & 4 & 98.5
\end{tabular}

Table 3 The risk of endometrial cancer at various endometrial thickness measurements in women who are symptomatic or asymptomatic with vaginal bleeding

\begin{tabular}{llc}
\hline $\begin{array}{l}\text { Threshold to define } \\
\text { a normal endometrium } \\
(\mathrm{mm})\end{array}$ & \multicolumn{2}{l}{$\begin{array}{l}\text { Women with vaginal bleeding: cancer } \\
\text { risk }(\%) \text { if the endometrium }\end{array}$} \\
\cline { 2 - 3 } & $\leq$ Threshold & $>$ Threshold \\
\hline$\leq 4$ & 0.07 & 4.6 \\
$\leq 5$ & 0.07 & 7.3 \\
$\leq 6$ & 0.08 & 7.7 \\
$\leq 7$ & 0.09 & 10.8 \\
$\leq 8$ & 0.12 & 12.7 \\
$\leq 9$ & 0.14 & 15.1 \\
$\leq 10$ & 0.18 & 16.6 \\
$\leq 11$ & 0.21 & 40.3 \\
$\leq 12$ & 0.25 & 42.1 \\
$\leq 13$ & 0.30 & 48.2 \\
$\leq 14$ & 0.36 & 52.2 \\
$\leq 15$ & 0.42 & 53.5 \\
\hline
\end{tabular}

have arisen regarding the appropriateness of performing biopsies on all patients with PMB. The authors, who have studied the above speculation, have reported conflicting results. The results of the Nordic multicenter trial [10] showed that it would seem justified to refrain from curettage, in women with PMB and an endometrium $\leq 4 \mathrm{~mm}$.

Moreover, it has been demonstrated by other teams [33] that if the false-negative rate of endometrial biopsy techniques is taken into account, then the combination of TVUS and cervical cytologic examination is an adequate form of management for women with PMB as long as endometrial thickness is $\leq 4 \mathrm{~mm}$.

Furthermore, as suggested by Ferrazzi et al. [18], transvaginal sonographic measurement of endometrial thickness, integrated with individual risk factors, can help in the management of postmenopausal patients with atypical bleeding (histological evaluation in high risk cases, or the choice of possible expectant management).
In 2001, the Society of Radiologists in Ultrasound met to discuss the role of sonography in women with PMB [36]. They concluded that PMB demands further evaluation and that either transvaginal sonography or endometrial biopsy could serve as the first-line diagnostic technique, but further studies are needed to determine which approach is more cost-effective.

In regard of an accurate clinical investigation, Gupta et al. [35], in their prospective study, recommended the combination of ultrasound and outpatient endometrial sampling in all women with PMB for excluding endometrial pathology.

In addition, the sum of the evidence from other studies [37] suggests that TVS and hysteroscopy are complementary diagnostic methods and could be accurately used to discriminate normal and pathologic conditions in patients with PMB. Several authors [38] have emphasized that there is a very good correspondence between hysteroscopy and histology (sensitivity $97.5 \%$ and specificity $100 \%$ ), confirming their usefulness in diagnosis of postmenopausal uterine bleeding. Consequently, in their opinion, hysteroscopy should be considered in all women with postmenopausal uterine bleeding.

It is also important to point out that there are conflicting reports about the case of rebleeding. Epstein et al. [6,7] observed that rebleeding and endometrial growth are common during a follow-up period of 12 months in women with PMB and an endometrial thickness $<5 \mathrm{~mm}$, irrespective of whether or not $\mathrm{d} \& \mathrm{c}$ is primarily carried out. According to their opinion, if these women are managed by ultrasound follow-up, endometrial sampling should be performed if the endometrium grows, but not necessarily in the case of rebleeding without endometrial growth. This view point is very well supported by the study of Van Doorn et al. [39]. According to the results of their study, $8 \%$ of the women with recurrent bleeding turned out to have an endometrial carcinoma. These women had presented with a first episode of PMB, an endometrial thickness $\leq 4 \mathrm{~mm}$ at TVUS and median time until recurrence of bleeding was 49 weeks. 


\section{Conclusions}

In summary, similar sensitivities for detecting endometrial carcinoma are reported for transvaginal sonography when an endometrial thickness of greater than $5 \mathrm{~mm}$ is considered abnormal and for endometrial biopsy when "sufficient" tissue is obtained. Despite the above outcome, controversy remains regarding the relative roles of these uterine imaging modalities. Future research needs to be directed toward providing effectiveness and cost-effectiveness. So, as the exclusion of endometrial cancer is very important and due to respect to woman's health and quality-of-life end points, there is an urgent need in the future for better quality primary accuracy studies using ideal reference standards and good-quality criteria to guide decision making.

\section{Conflict of interest None.}

Open Access This article is distributed under the terms of the Creative Commons Attribution Noncommercial License which permits any noncommercial use, distribution, and reproduction in any medium, provided the original author(s) and source are credited.

\section{References}

1. ACOG committee opinion no. 426 (2009) The role of transvaginal ultrasonography in the evaluation of postmenopausal bleeding. American College of Obstetricians and Gynecologists. Obstet Gynecol 113(2 Pt 1):462-464

2. Gemer O, Segal S (1998) Endometrial cancer in patients undergoing diagnostic curettage. Arch Gynecol Obstet 261(2):79-81

3. Bourne T, Hamberger L, Hahlin M, Granberg S (1997) Ultrasound in gynecology: endometrium. Int J Gynecol Obstet 56:115-127 (review article)

4. Elsandabesee D, Greenwood P (2005) The performance of Pipelle endometrial sampling in a dedicated postmenopausal bleeding clinic. J Obstet Gynaecol 25:32-34

5. Dubinsky T (2004) Value of sonography in the diagnosis of abnormal vaginal bleeding. J Clin Ultrasound 32(7):348-353

6. Epstein E, Valentin L (2006) Gray-scale ultrasound morphology in the presence or absence of intrauterine fluid and vascularity as assessed by color Doppler for discrimination between benign and malignant endometrium in women with postmenopausal bleeding. Ultrasound Obstet Gynecol 28:89-95

7. Epstein E, Skoog L, Isberg P-E, De Smet F, De Moor B, Olofsson P-E, Gudmundsson S, Valentin L (2002) An algorithm including results of gray-scale and power Doppler ultrasound examination to predict endometrial malignancy in women with postmenopausal bleeding. Ultrasound Obstet Gynecol 20:370-376

8. Dragojevic S et al (2005) The role of transvaginal colour Doppler sonography in evaluation of abnormal uterine bleeding. Arch Gynecol Obstet 271(4):332-335

9. Kanat-Pektas M, Gungor T, Mollamahmutoglu L (2008) The evaluation of endometrial tumors by transvaginal and Doppler ultrasonography. Arch Gynecol Obstet 277(6):495-499

10. Karlsson B, Granberg S, Wikland M, Ryd W, Norstrom A (1993) Endovaginal scanning of the endometrium compared to cytology and histology in women with postmenopausal bleeding. Gynecol Oncol 50:173-178
11. Auslender R (1993) Vaginal ultrasound in patients with postmenopausal bleeding. Ultrasound Obstet Gynecol 3:426-428

12. Dijkhuizen FP, Mol BW, Brolmann HA, Heintz AP (2000) The accuracy of endometrial sampling in the diagnosis of patients with endometrial carcinoma and hyperplasia: a meta-analysis. Cancer 89:1765-1772

13. Granberg S, Wikland M, Karlsson B, Norstrom A, Friberg LG (1991) Endometrial thickness as measured by endovaginal ultrasonography for identifying endometrial abnormality. Am J Obstet Gynecol 164:47-52

14. Nasri MN, Shepherd JH, Setchell ME, Lowe DG, Chard T (1991) The role of vaginal scan in measurement of thickness in postmenopausal women. Br J Obstet Gynaecol 98:470-475

15. Goldstein SR, Nachtigall M, Snyder JR, Nachtigall L (1990) Endometrial assessment by vaginal ultrasonography before endometrial sampling in patients with postmenopausal bleeding. Am J Obstet Gynecol 163:119-123

16. Buyuk E, Durmusoglu F, Erenus M et al (1999) Endometrial disease diagnosed by transvaginal ultrasound and dilation and curettage. Acta Obstet Gynecol Scand 78:419

17. Botsis D, Kassanos D, Pyrgiotis E, Zourlas PA (1992) Vaginal sonography of the endometrium in postmenopausal women. Clin Exp Obstet Gynecol 19:189-192

18. Ferrazzi E, Torri V, Trio D, Zannoni E, Filiberto S, Dordoni D (1996) Sonographic thickness. A useful test to predict atrophy in patients with postmenopausal bleeding. An Italian multicenter study. Ultrasound Obstet Gynecol 7(5):315-321

19. Granberg S, Ylostalo P, Wikland M, Karlsson B (1997) Endometrial sonographic and histologic findings in women with and without hormonal replacement therapy suffering from postmenopausal bleeding. Maturitas 27:35-40

20. Garuti G, Sambruni I, Cellani F, Garzia D, Alleva P, Luerti M (1999) Hysteroscopy and transvaginal ultrasonography in postmenopausal women with uterine bleeding. Int J Gynecol Obstet $65: 25-33$

21. Bakour SH, Dwarakanath LS, Khan KS, Newton JR, Gupta JK (1999) The diagnostic accuracy of ultrasound scan in predicting endometrial hyperplasia and cancer in postmenopausal bleeding. Acta Obstet Gynecol Scand 78:447-451

22. Ciatto S, Cecchini S, Gervasi G, Landini A, Zappa M, Crocetti E (2002) Association of endometrial thickness assessed at trans-vaginal ultrasonography to endometrial cancer in postmenopausal asymptomatic or with abnormal uterine bleeding. Radiol Med 104(5-6):437-442

23. Guner H, Tiras MB, Karabacak O, Sarikaya H, Erdem M, Yildirim M (1996) Endometrial assessment by vaginal ultrasonography might reduce endometrial sampling in patients with postmenopausal bleeding: a prospective study. Aus NZ J Obstet Gynaecol 36:175-178

24. Tsikouras P, Liberis V, Galazios G, Grapsas X, Kantari P, Papageorgiou S, Maroulis G (2008) TV sonographic assessment in postmenopausal women with bleeding. Eur J Gynecol Oncol XXIX(1):67-71

25. Briley M, Lindsell DRM (1998) The role of transvaginal ultrasound in the investigation of women with post-menopausal bleeding. Clin Radiol 53:502-505

26. Gupta JK, Wilson S, Desai P, Hau C (1996) How should we investigate women with postmenopausal bleeding? Acta Obstet Gynecol Scand 75:475-479

27. Bruchim I, Biron-Shental T, Altaras MM, Fishman A, Beyth Y, Tepper R, Aviram R (2004) Combination of endometrial thickness and time since menopause in predicting endometrial cancer in women with postmenopausal bleeding. J Clin Ultrasound 32(5):219-224

28. Gull B, Carlsson S, Karlsson B, Ylostalo P, Milsom I, Granberg S (2000) Transvaginal ultrasonography of the endometrium in wom- 
en with postmenopausal bleeding. Is it always necessary to perform an endometrial biopsy? Am J Obstet Gynecol 182:509-515

29. Gull B, Karlsson B, Milsom I, Granberg S (2003) Can ultrasound replace dilation and curettage? A longitudinal evaluation of postmenopausal bleeding and transvaginal sonographic measurement of the endometrium as predictors of endometrial cancer. Am J Obstet Gynecol 188(2):401-408

30. Develioglu OH et al (2003) Transvaginal ultrasonography and uterine artery Doppler in diagnosing endometrial pathologies and carcinoma in postmenopausal bleeding. Arch Gynecol Obstet 268(3): 175-180

31. Mateos F, Zarauz R, Seco C, Rayward JR, del Barrio P, Aguirre J et al (1997) Assessment with transvaginal ultrasonography of endometrial thickness in women with postmenopausal bleeding. Eur J Gynaecol Oncol 18:504-507

32. Epstein E, Skoog L, Valentin L (2001) Comparison of Endorette and dilatation and curettage for sampling of the endometrium inwomen with postmenopausal bleeding. Acta Obstet Gynecol Scand 80:959-964

33. Fleischer AC, Kalemeris GC, Machin JE (1986) Sonographic depiction of normal and abnormal endometrium with histopathologic correlation. J Ultrasound Med 5:445-452

34. Smith-Bindman R, Weiss E, Feldstein V (2004) How thick is too thick? When endometrial thickness should prompt biopsy in postmenopausal women without vaginal bleeding. Ultrasound Obstet Gynecol 24:558-565

35. Gupta JK, Chien PF, Voit D, Clark TJ, Khan KS (2002) Ultrasonographic endometrial thickness for diagnosing endometrial pathology in women with postmenopausal bleeding: a metaanalysis. Acta Obstet Gynecol Scand 81:799-816

36. Goldstein RB, Bree RL, Benson CB, Benacerraf BR, Bloss JD, Carlos R et al (2001) Evaluation of the woman with postmenopausal bleeding: society of radiologists in ultrasound sponsored consensus conference statement. J Ultrasound Med 20:1025-1036

37. Haller H, Matejcic N, Rukavina B, Krasevic M, Rupcic S, Mozetic D (1996) Transvaginal sonography and hysteroscopy in women with postmenopausal bleeding. Int J Gynecol Obstet 54:155-159

38. Loverro G, Bettocchi S, Cormio G, Nicolardi V, Greco P, Vimercati A et al (1999) Transvaginal sonography and hysteroscopy in postmenopausal uterine bleeding. Maturitas 33:139-144

39. Van Doorn HC, Timmermans A, Opmeer BC, Kruitwagen RF, Dijkhuizen FP, Kooi GS, Van De Weijer PH, Mol BW, Dupomeb $F$ et al (2008) What is the recurrence rate of postmenopausal bleeding in women with a thin endometrium during a first episode of postmenopausal bleeding. Acta Obstet Gynecol Scand 87(1): 89-93 